\title{
Effect of Adjuvant (Hormonal) Therapy on Bone Mineral Density in Caucasian Women with Breast Cancer
}

\author{
Nana Khachidze, MD \\ Ivane Javakhishvili Tbilisi State University (TSU), Tbilisi, Georgia \\ Elene Giorgadze, $\mathrm{MD}, \mathrm{PhD}$
}

Ivane Javakhishvili Tbilisi State University (TSU), Tbilisi, Georgia

National Institute of Endocrinology, Tbilisi, Georgia

Marina Tsagareli, $\mathrm{MD}, \mathrm{PhD}$

Nino Dolidze, MD, PhD

Tea Sulikashvvili, $M D$

National Institute of Endocrinology, Tbilisi, Georgia

doi: 10.19044/esj.2017.v13n18p1 URL:http://dx.doi.org/10.19044/esj.2017.v13n18p1

\begin{abstract}
Background and Aim: Aromatase inhibitors (AIs) and selective estrogen receptor modulators (SERMs) are important components of adjuvant endocrine therapy in postmenopausal women with estrogen receptor positive breast cancer. The aim of our study was to assess the effect of AIs and SERMs on bone mineral density (BMD) in Caucasian postmenopausal women with breast cancer. Patients and Methods: 118 postmenopausal Caucasian women were enrolled in the study. 60 patients were receiving AIs and 58 patients - SERMs-Tamoxifen. Patients were also divided into two sub groups: 1) patients with more than 3 years of last menstrual period (LMP) and 2) patients with less than 3 years of last menstrual period. Results: Among Aromatase inhibitors treated patients, there was a decrease in median BMD from baseline to 5 years in lumbar spine and total hip compared with the Tamoxifen group. No patients with normal BMD at baseline became osteoporotic at 5 years. Conclusion: Aromatase inhibitors are associated with accelerated bone loss over the 5-year treatment period. In postmenopausal women, treatment with tamoxifen is associated with preservation of the bone mineral density of the lumbar spine
\end{abstract}

Keywords: Aromatase inhibitors; Selective estrogen receptor modulators; Bone mineral density; Dual Energy X-ray Absorptiometry; Last menstrual period. 


\section{Introduction}

Estrogens play an important role in female bone homeostasis (Leslie, et al., 1995); in the estrogen deficient state, bone resorption is increased (Chapurlat, et al., 2000; Ettinger, et al., 1998; Rogers, et al., 2002). As a result of these predictable postmenopausal findings, estrogens have been extensively used as the main therapy to prevent bone loss in postmenopausal women. Estrogens reduce bone turnover rate and, as an antiresorptive, clearly improve bone density (Rossouw, et al., 2002) .

In the 10 years following the menopause, there is a reduction in BMD averaging $2 \%$ per annum, and osteoporosis is a major cause of morbidity in postmenopausal women.

Tamoxifen is a synthetic antiestrogen that, since its introduction for the treatment of patients with breast cancer in the early 1970s, has come to have a major role in the management of all stages of the disease (Love, et al., 1989). More recently, tamoxifen has been proved to have a favorable effect on disease-free and overall survival when given as adjuvant therapy after primary treatment for invasive breast cancer.

Aromatase inhibitors: Anastrozole and Letrozole -nonsteroidal aromatase inhibitors are hormone therapy drugs that can slow or stop the growth of hormone receptor-positive tumors. They lower estrogen levels in the body by blocking aromatase, an enzyme that converts other hormones into estrogen. This prevents the cancer cells from getting the hormones they need to grow.

Aromatase inhibitors cause a loss of bone density, which leads to higher rates of osteoporosis and bone fractures compared to tamoxifen (Perez, et al., 2006; Amir, et al., 2011).

Tamoxifen is not a pure antiestrogen; it has some estrogen-agonist properties, such as the ability to decrease the serum concentrations of cholesterol and increase those of sex-hormone-binding globulin (Love, et al., 1990) .

The beneficial effects of tamoxifen on BMD are most apparent at sites of trabecular bone, such as the lumbar spine (Grey, et al., 1995); such protective effects are associated with decreased bone resorption and formation (Marttunen, et al., 1999) .

In our study, we report the 5-years results of adjuvant (hormonal) therapy on bone mineral density in Caucasia women with breast cancer.

\section{Materials and Methods Patients}

118 Caucasian postmenopausal women (between 46-74 years) were enrolled in this study at the National Institute of Endocrinology, Metabolic Disorders in Georgia. The study was approved by the ethical committee of 
the National Institute of Endocrinology according to the declaration of Helsinki.

60 patients were receiving Aromatase inhibitors - Anastrozole or Letrozole, 58 patients - selective estrogen receptor modulators - Tamoxifen. We have measured Lumbar Spine (LS) and Total Hip (TH) BMDs, values were obtained using Dual Energy X-ray absorptiometry (DXA).

38 postmenopausal women with invasive breast cancer were also enrolled in the study as control group. These patients were not receiving any treatment after primary surgery.

T-score $>-2.5$ was exclusion criteria, so patients with osteoporosis were not enrolled in our study.

\section{Assessments}

Lumbar spine and Total hip BMD assessments were done at baseline, after 1, 2, and 5 years of therapy by dual energy x-ray absorptiometry.

For the lumbar spine, DXA measurement was derived by taking an average of the L1, L2, L3, and L4 values. Total hip BMD was calculated from the ratio of the total bone mineral content and bone area from the trochanteric, intertrochanteric, and femoral neck regions of the hip.

\section{Results \\ Patients}

60 postmenopausal Caucasian women received AI and 58 Tamoxifen. 38 postmenopausal women (as control group) with invasive breast cancer not receiving any treatment after primary surgery. They all had a baseline DXA.

The mean age at entry was 56 years. At baseline, approximately $58 \%$ patients from anastrozole or letrozole group, $22 \%$ patients from tamoxifen group and $29 \%$ of the control group had osteopenia of the lumbar spine. Both treatment groups and control group had osteopenia also in total hip (28\% in AI group; $10 \%$ in Tamoxifen group and $21 \%$ in control group).

Most of the patients in the tamoxifen and the control group were within 3 years of menopause compared with the anastrozole and letrozole group.

\section{Effect of Treatment on BMD}

Among Aromatase inhibitors treated patients, there was a decrease in median BMD from baseline to 5 years in lumbar spine (patients with > 3 years of LMP $-5,22 \%$ and patients with $<3$ years of LMP - 10,08\%) and total hip (patients with $>3$ years of LMP $-6,52 \%$ and patients with $<3$ years of LMP - 6,10\% compared with the Tamoxifen group (lumbar spine : patients with $>3$ years of LMP $+2,62 \%$ and patients with $<3$ years of LMP 
$+3,54 \%$; total hip: patients with $>3$ years of LMP $+0,03 \%$ and patients with $<3$ years of LMP $+2,03 \%$ ). No patients with normal BMD at baseline became osteoporotic at 5 years. BMD changes are listed in Table 1 and Figure 1.

\begin{tabular}{|c|c|c|c|c|c|}
\hline & \multirow[b]{2}{*}{ Treatment groups } & \multirow[b]{2}{*}{$\begin{array}{l}\text { Number of } \\
\text { patients }\end{array}$} & \multicolumn{3}{|c|}{ Median $\%$ change from baseline } \\
\hline & & & 1 Year & 2 Years & 5 Years \\
\hline \multirow{4}{*}{ 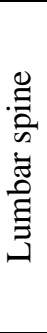 } & $\begin{array}{l}\text { Aromatase inhibitor } \\
\text { (>3 Years since LMP) }\end{array}$ & 46 & $-1,61 \%$ & $-3,02 \%$ & $-5,22 \%$ \\
\hline & $\begin{array}{l}\text { Aromatase inhibitor } \\
(<3 \text { Years since LMP) }\end{array}$ & 14 & $-5,01 \%$ & $-6,32 \%$ & $-10,08 \%$ \\
\hline & $\begin{array}{c}\text { Tamoxifen }(>3 \text { Years } \\
\text { since LMP) }\end{array}$ & 16 & $0,87 \%$ & $2,03 \%$ & $2,62 \%$ \\
\hline & $\begin{array}{c}\text { Tamoxifen }(<3 \text { Years } \\
\text { since LMP })\end{array}$ & 42 & $2,01 \%$ & $2,87 \%$ & $3,54 \%$ \\
\hline \multirow{4}{*}{ 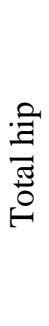 } & $\begin{array}{l}\text { Aromatase inhibitor } \\
(>3 \text { Years since LMP) }\end{array}$ & 46 & $-1,25 \%$ & $-3,27 \%$ & $-6,52 \%$ \\
\hline & $\begin{array}{l}\text { Aromatase inhibitor } \\
(<3 \text { Years since LMP) }\end{array}$ & 14 & $-2,20 \%$ & $-3,27 \%$ & $-6,10 \%$ \\
\hline & $\begin{array}{c}\text { Tamoxifen (>3 Years } \\
\text { since LMP) }\end{array}$ & 16 & $0,71 \%$ & $1,03 \%$ & $0,03 \%$ \\
\hline & $\begin{array}{c}\text { Tamoxifen }(<3 \text { Years } \\
\text { since LMP })\end{array}$ & 42 & $0,72 \%$ & $1,69 \%$ & $2,03 \%$ \\
\hline
\end{tabular}

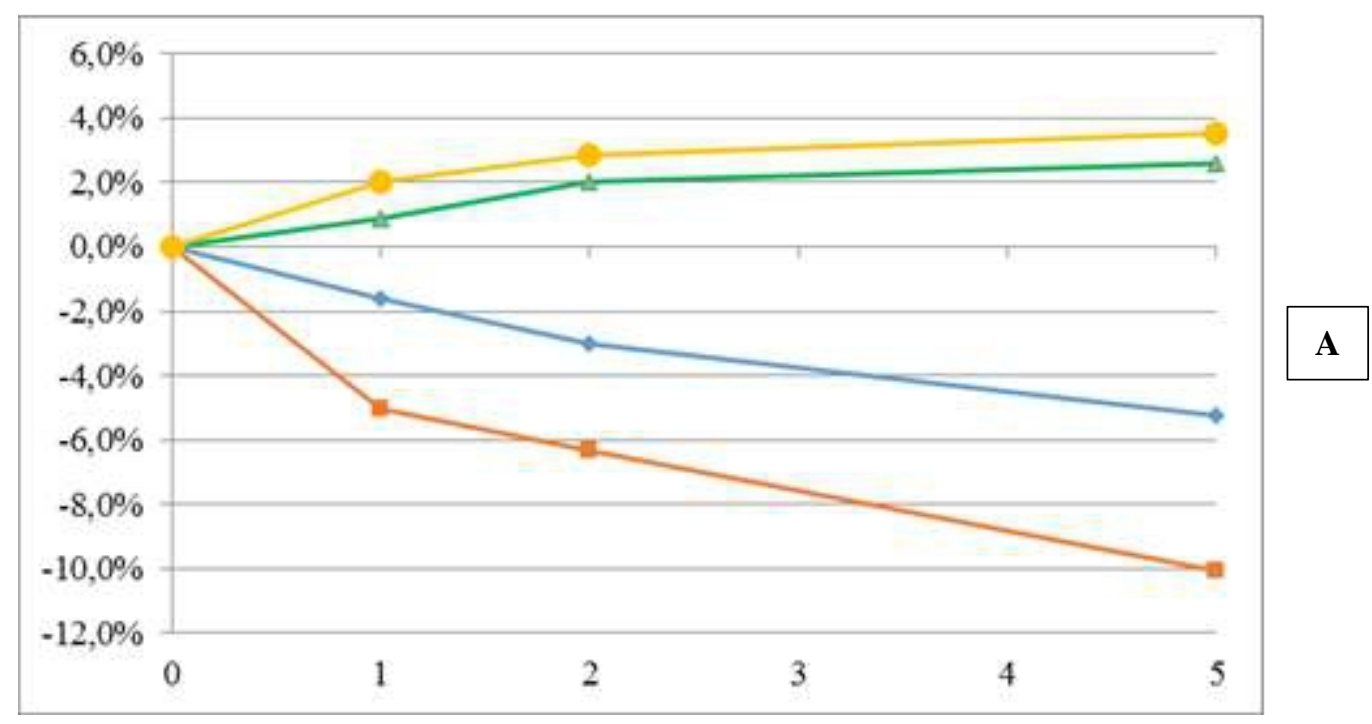




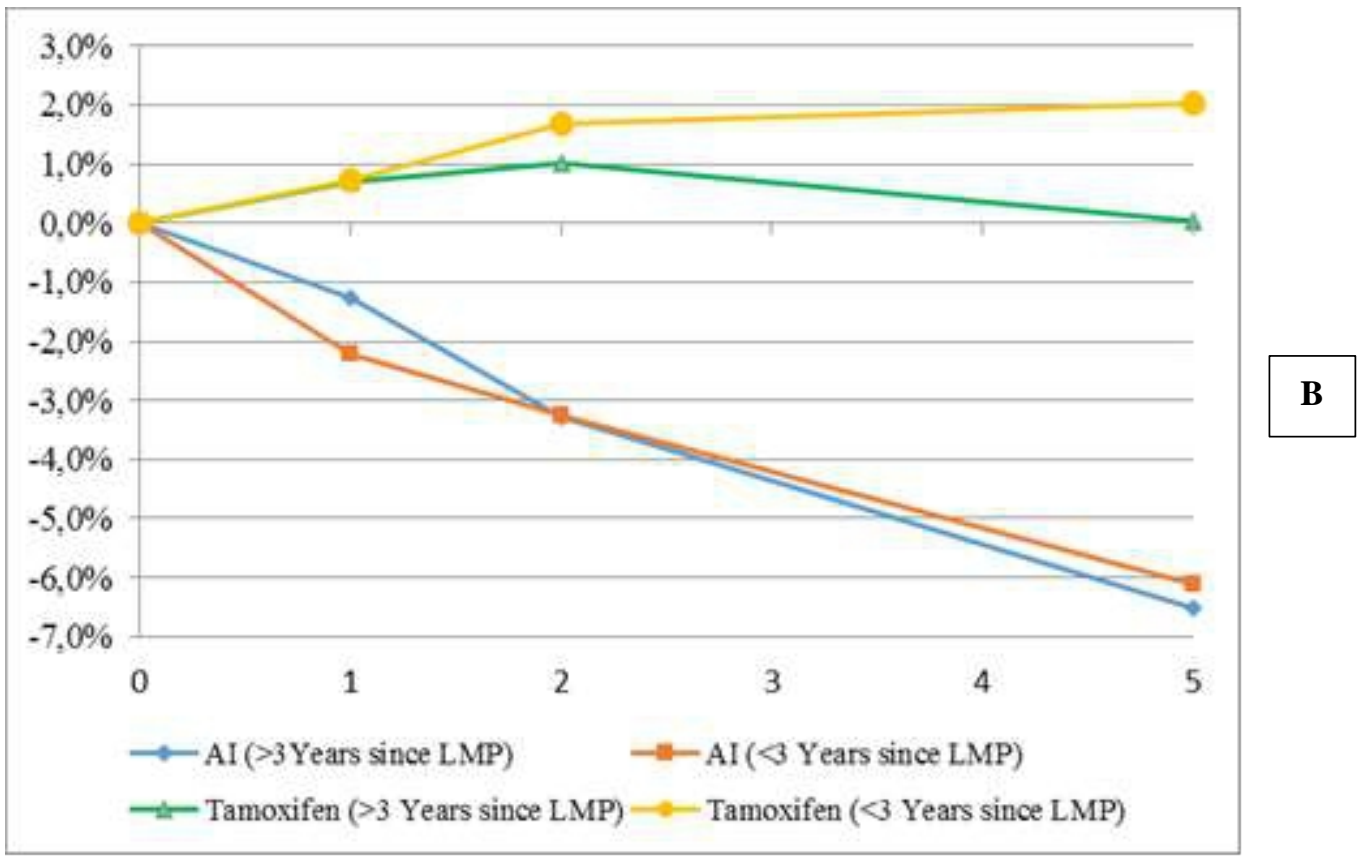

Fig 1. Mean percentage changes in bone mineral density after 1, 2 and 5 years. Lumbar spine change over time and B. total hip change over time

The control group showed changes in median BMD over the 5-year period (lumbar spine $+1,29 \%$; total hip $+2,31 \%$ ).

Patients with normal BMD at baseline, who received treatment (anastrozole or letrozole - n 60; or tamoxifen- n 58), none had become osteoporotic (T-score <-2.5) at 5 years. Only 3 women with osteopenia at baseline developed osteoporosis on AI treatment.

\section{Discussion}

At the end of our study all BMD data showed significant bone loss in aromatase inhibitors treated patients relative to SERMs treated postmenopausal women. The rapid bone loss occurred in lumbar spine from baseline to 2 years compared with 2 to 5 years.

It is known that bone loss accelerates substantially in the late perimenopause and continues at a similar pace in the first postmenopausal years (Joel, et al., 2008).

We also found out that the rate of BMD loss at 1,2 , and 5 years at the lumbar spine for AI group was greater for women in the immediate postmenopausal period (within 3 years of their last menstrual period) than for patients more than 3 years since their menopause.

Breast cancer patients treated with tamoxifen showed protection against postmenopausal bone loss (Powles, et al., 1996). 
We noticed that at 1,2 , and 5 years BMD increase was greater in Tamoxifen group patients within 3 years of their last menstrual period. Patients in the control group experienced little change in lumbar spine and total hip BMD.

The current analysis shows that no woman with a normal BMD at baseline had become osteoporotic at 5 years and the data suggest that only those women with a T-score of less than - 1.5 are at risk of developing osteoporosis during the treatment period.

Based on this, we can say that if pre-existing osteopenia is excluded no further preventive actions are required for all postmenopausal women.

For patients with pre-existing osteopenia (and risk factors including age, family history, smoking, and concomitant use of drugs such as corticosteroids), who are on AI treatment regular monitoring of BMD and bone-protection strategies are necessary.

Clinical trial evidence indicates that intravenous (Gnant, et al., 2009; Stephanie, et al., 2010; Brufsky et al., 2007) and oral bisphosphonates (Delmas, et al., 1997; Lester, et al., 2008; Van Poznak, et al., 2005) are effective in maintaining BMD in breast cancer patients receiving hormonal (endocrine) therapy.

Given that AIs reduce estrogen levels by approximately $90 \%$, it might be expected that bone loss would be accelerated. However, it is critical to understand the relationship between AIs and fracture risk (Eastell, et al., 2005).

Overall, findings from our study suggest that adjuvant anastrozole/letrozole therapy for postmenopausal women with early breast cancer leads to accelerated bone loss. Many studies suggest that the risk of developing treatment-related osteoporosis seems to be confined to those patients already osteopenic at baseline, and other data suggest that bone loss can be managed in this group by DXA scanning and use of bisphosphonates as needed.

\section{Conclusion}

The present study showed that Aromatase inhibitors are associated with accelerated bone loss over the 5-year treatment period. The rapid bone loss occurred in lumbar spine from baseline to 2 years compared with 2 to 5 years. In postmenopausal women, treatment with tamoxifen is associated with preservation of the bone mineral density of the lumbar spine.

\section{References:}

1. Leslie WD, Cowden EA, Maclean JP. Oestrogen and bone density: a comparison of tamoxifen and hypo-oestrogenaemia. Nucl Med Commun. 1995 Aug;16(8):698-702. 
2. Chapurlat RD, Garnero P, Bréart G, Meunier PJ, Delmas PD. Serum estradiol and sex hormone-binding globulin and the risk of hip fracture in elderly women: the EPIDOS study. J Bone Miner Res. 2000 Sep;15(9):1835-1841.

3. Ettinger B, Pressman A, Sklarin P, Bauer DC, Cauley JA, Cummings SR. Associations between low levels of serum estradiol, bone density, and fractures among elderly women: the study of osteoporotic fractures. J Clin Endocrinal Metab. 1998 Jul;83(7):22392243.

4. Rogers A, Saleh G, Hannon RA, Greenfield D, Eastell R. Circulating estradiol and osteoprotegerin as determinants of bone turnover and bone density in postmenopausal women. $\mathrm{J}$ Clin Endocrinol Metab. 2002 Oct;87(10):4470-4475.

5. Rossouw JE, Anderson GL, Prentice RL, et al. Risks and benefits of estrogen plus progestin in healthy postmenopausal women: principal results from the Women's Health Initiative randomized controlled trial. JAMA. 2002 Jul 17;288(3):321-333.

6. Love RR; Tamoxifen Therapy in Primary Breast Cancer: Biology, Efficacy, and Side Effects. J Clin Oncol. 1989 Jun;7(6):803-815.

7. Perez EA1, Weilbaecher K. Aromatase Inhibitors and Bone Loss. Oncology (Williston Park). 2006 Aug; 20(9): 1029-1048.

8. Amir E, Seruga B, Niraula S, Carlsson L, Ocaña. A. Toxicity of adjuvant endocrine therapy in postmenopausal breast cancer patients: a systematic review and meta-analysis. J Natl Cancer Inst. 2011 Sep 7;103(17):1299-12309.

9. Love RR, Newcomb PA, Wiebe DA, et al. Effects of tamoxifen therapy on lipid and lipoprotein levels in postmenopausal patients with node-negative breast cancer. J Natl Cancer Inst. 1990 Aug 15;82(16):1327-1332.

10. Grey, A.B., Stapleton, J.P., Evans, M.C. et al. The effect of the antiestrogen tamoxifen on bone mineral density in normal late postmenopausal women. Am J Med. 1995 Dec; 99:636-641.

11. Marttunen MB, Hietanen P, Titinen A, et al. Effects of tamoxifen and toremifene on urinary excretion of pyridinoline and deoxypyridinoline and bone density in postmenopausal patients with breast cancer. Calcif Tissue Int. November 1999, Volume 65, Issue 5: 365-368

12. Joel S. Finkelstein, Sarah E. Brockwell, Vinay Mehta, et al. Bone Mineral Density Changes during the Menopause Transition in a Multiethnic Cohort of Women. J Clin Endocrinol Metab. 2008 Mar; 93(3): 861-868. 
13. Powles TJ, Hickish T, Kanis JA, Tidy A, Ashley S. Effect of tamoxifen on bone mineral density measured by dual-energy $\mathrm{x}$-ray absorptiometry in healthy premenopausal and postmenopausal women. J Clin Oncol. 1996 Jan;14(1):78-84.

14. Gnant M, Mlineritsch B, Schippinger W, et al. Endocrine therapy plus zoledronic acid in premenopausal breast cancer. $\mathrm{N}$ Engl $\mathrm{J}$ Med. 2009 Feb 12;360(7):679-691.

15. Stephanie L. Hines, Jeff A. Sloan, Pamela J. Atherton, et al . Zoledronic Acid for Treatment of Osteopenia and Osteoporosis in Women with Primary Breast Cancer Undergoing Adjuvant Aromatase Inhibitor Therapy. J Breast. 2010 Apr; 19(2): 92-96.

16. Brufsky A, Harker WG, Beck JT, et al: Zoledronic acid inhibits adjuvant letrozole-induced bone loss in postmenopausal women with early breast cancer. J Clin Oncol. 2007 Mar 1;25(7):829-836.

17. Delmas PD, Balena R, Confravreux E, Hardouin C, Hardy $\mathrm{P}$, Bremond A. Bisphosphonate risedronate prevents bone loss in women with artificial menopause due to chemotherapy of breast cancer: a double-blind, placebo-controlled study. J Clin Oncol. 1997 Mar;15(3):955-962.

18. Lester JE, Dodwell D, Purohit OP et al. Prevention of anastrozoleinduced bone loss with monthly oral ibandronate during adjuvant aromatase inhibitor therapy for breast cancer. Clin Cancer Res. 2008 Oct 1;14(19):6336-6342.

19. Van Poznak C, Hannon RA, Mackey JR et al. Prevention of aromatase inhibitor induced bone loss using risedronate: the SABRE trial. J Clin Oncol. 2010 Feb 20;28(6):967-975

20. Eastell R, Hannon R. Long-term effects of aromatase inhibitors on bone. J Steroid Biochem Mol Biol. 2005 May;95(1-5):151-154. 